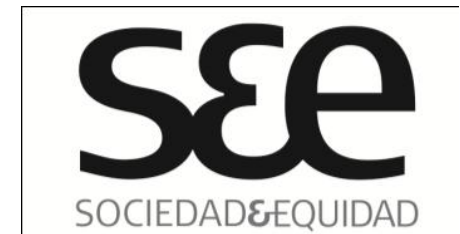

SOCIEDADEEQUIDAD

\section{Huelga de Hambre: \\ Dolor, Sufrimiento y Visibilización del Conflicto Social}

Hunger Strike: Pain, Suffering and Visibility of Social Conflict

Nombre:

Filiación:

País:

Correo:

\author{
Sergio Urzúa Martínez ${ }^{(1)}$ \\ Investigador independiente \\ Chile \\ sergio_urzua_m@yahoo.es
}

\title{
RESUMEN
}

El presente trabajo es una reflexión teórica a propósito de la huelga de hambre adoptada por los estudiantes chilenos en el marco del movimiento estudiantil de 2011. En dicho contexto, la huelga de hambre, se constituye como una herramienta que permite visibilizar el sufrimiento y desnaturalizar la represión por medio de un acto sacrificial donde los cuerpos se exponen al dolor. Es justamente esta exposición, la que permite que los sectores dominados irrumpan en el espacio público, disputen su hegemonía y logren un reconocimiento social del conflicto. Su carácter público, conciente, pacífico y moralmente fundado permite que sea interpretado como un acto de desobediencia civil que pone en cuestión la frágil democracia chilena.

\section{PALABRAS CLAVES}

Huelga de hambre, sufrimiento, sacrificio, conflicto social.

\footnotetext{
${ }^{1}$ El autor es Magíster $\odot$ en Sociología de la Universidad Alberto Hurtado y Profesor de Estado en Filosofía de la Universidad de Santiago de Chile. Sus líneas de investigación son cuerpos y emociones, acción colectiva y conflicto social.
} 


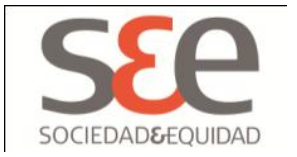

\section{ABSTRACT}

This paper is a theoretical reflection about the hunger strike conducted by Chilean students under the student movement of 2011. In this context, the hunger strike, was established as a tool to visibilize the suffering and denaturalize the repression through a sacrificial act where the bodies are exposed to pain. It is precisely this exhibition that allows dominated sectors to break into the public space, dispute their hegemony and achieve social recognition of the conflict. Its public, aware, peaceful and morally founded nature, allows for it to be interpreted as an act of civil disobedience that challenges the fragile democracy in Chile.

\section{KEYWORDS}

Hunger strike, suffering, sacrifice, social conflict.

\section{Introducción ${ }^{2}$}

Los altos niveles de desigualdad en la distribución de los recursos y del bienestar, la privatización de la seguridad y de las oportunidades, sumado a los escasos espacios formales de participación ciudadana, son algunos de los elementos que permiten situar el sufrimiento en Chile.

Sin embargo, en vez de atender el sufrimiento que emerge, muchas veces expresado como malestar, se reprime silenciando y violentando los cuerpos. La represión termina invisivilizando no sólo las razones del sufrimiento, sino también a quienes sufren. En este sentido, en la represión subyace la negación del otro, que se expresa en el disciplinamiento de los cuerpos y de las emociones, lo que posibilita maximizar la explotación y asegurar con esto, el fértil desarrollo del capitalismo. Es por esto, que el presente trabajo se propone analizar teóricamente la dimensión sacrificial de la huelga de hambre, en tanto acción reflexiva, que permite mediante el dolor físico visibilizar el sufrimiento.

En este sentido, las preguntas que se intentarán responder respecto de la huelga de hambre levantada por los estudiantes chilenos en el marco de las protestas por la educación durante el año 2011, pueden sintetizarse en ¿cuáles son los

\footnotetext{
${ }^{2}$ El presente trabajo es fruto de las reflexiones realizadas en el marco de las reuniones de la línea de "Disciplinamiento y Normalización" del Núcleo de Investigación de Sociología del Cuerpo de la Universidad de Chile.
} 


\section{s\&e \\ SOCIEDADEEQUIDAD}

elementos que posibilitan su emergencia como fenómeno social, y por qué se constituye como una herramienta de alto impacto social?

Para esto se presentará, en primer lugar, una distinción entre "dolor físico" y "sufrimiento" o "dolor social" para luego explicar cómo, mediante el primero, es posible objetivar el segundo y hacerlo visible. A continuación, se dará cuenta de las características del acto sacrificial en las sociedades modernas, donde se analizará la tensión que hay entre el individuo y el colectivo, que para los efectos de este trabajo, se refiere al acto conciente de autodonación para el beneficio de la sociedad toda. Al mismo tiempo, se examinará el cuerpo entregado en sacrificio, en tanto locus de las fuerzas, elemento central en el esquema de explotación capitalista, situación que hace posible interpretar la huelga de hambre como un acto de desobediencia civil. Por último, se observará cómo la represión ha sido convertida en una política de Estado en Chile (cuyo origen se encuentra en la doctrina portaliana de "orden y paz social" vigente hasta nuestros días) para desde ahí, entender el poder que ejercen los "mecanismos de soportabilidad social", los que se manifiestan en estados de "impotencia social" que tienden a inhibir las acciones políticas colectivas y a contener la eclosión social.

De esta forma, se articularán estos tres ejes para intentar explicar el carácter y el impacto en la reafirmación del conflicto y en la disputa del espacio público, que tiene la huelga de hambre, asumiendo ésta como una estrategia de visibilización emprendida por los estudiantes.

\section{El "dolor físico" como visibilización del sufrimiento}

El día martes 19 de julio del 2011, ocho estudiantes secundarios del liceo A-131 de Buin, iniciaban una huelga de hambre en el marco de las manifestaciones por una educación pública, gratuita y de calidad en Chile. En los días que siguieron la medida fue adoptada por más jóvenes de distintas regiones del país.

A medida que los cuerpos se adelgazan y el estado de salud de los jóvenes empeora, la atención se vuelca sobre aquellos cuerpos sufrientes y dolientes.

La primera distinción que se introducirá, dice relación con los conceptos de “dolor físico" y "sufrimiento" o "dolor social” (Scribano, 2007b). El dolor corporal se nos presenta como un desajuste o desequilibrio a corregir, en tanto irrumpe en el cuerpo, lo perturba, demanda atención y requiere ser calmado. El dolor es un espectáculo violento en el marco de las sociedades modernas donde prima un enfoque anestésico. Así, se incorpora como un derecho el no tener que sufrir dolor, allí donde existen los medios técnicos para suprimirlo (Brossat, 2008).

En este sentido el dolor no sólo recuerda la fragilidad del ser humano, sino también un estado precivilizado, ya que como señala Brossat (2008). "El dolor sufrido se asemeja a una forma de decadencia, la condición del que está preso de un dolor 


\section{S\&e \\ SOCIEDADEEQUIDAD}

inmenso o persistente, es percibida como rebaja, deshumanizada" (Brossat, 2008:59). De esta forma, "rechazamos el dolor y lo consideramos como una anomalía, una perturbación ilegítima" (Brossat, 2008:68), que debe ser atendida y tratada, como una exigencia moral. El dolor nunca es indiferente, ya que despierta en los individuos las más variadas emociones, lo que hace que se posicionen frente a éste.

El "sufrimiento" o "dolor social", en tanto, al igual que el dolor físico, se presenta como un desequilibrio, pero ya no a escala corporal sino psicológica. El sufrimiento se manifiesta mediante la angustia y la inseguridad que tienen las personas frente a las relaciones de poder que las someten. El sufrimiento no es fácilmente observable, es una experiencia enteramente subjetiva, lo que implica un mayor esfuerzo en su objetivación ${ }^{3}$ para que pueda ser comunicada efectivamente ${ }^{4}$.

Dicho esto, podemos afirmar que la huelga de hambre como objeto social, permitiría expresar el sufrimiento mediante el dolor corporal, de modo de hacerlo visible y comunicable. En otras palabras, es un intento por materializar aquellos elementos que se encuentran en el plano interno, de modo de mostrar por medio del dolor corporal, el sufrimiento del alma.

Resulta, entonces, necesario preguntarse ¿cuál es la causa del sufrimiento que aqueja a los estudiantes chilenos hoy?

El punto de partida lo encontramos en el diagnóstico que realiza Svampa (2008), quien entrega elemento en relación a las transformaciones estructurales que han sufrido las sociedades de América Latina, pero que no se agotan en éstas, sino que constituyen un complejo de relaciones fundadas en la exclusión y la desigualdad en el marco de las economías neoliberales. De esta forma, sostiene:

(...) el pasaje a la globalización neoliberal, por medio de las reformas llamadas 'estructurales', significó en América Latina la acentuación de desigualdades preexistentes y la emergencia de nuevas brechas políticas, económicas, sociales y culturales. Este proceso de redistribución condujo a un

\footnotetext{
${ }^{3}$ Es necesario distinguir entre 'objetividad' y 'objetivación'. La objetividad está relacionada con una cualidad del objeto en sí mismo, en tanto, no necesita de un sujeto o mediador externo que decida cuál es la esencia del objeto. Esto, a diferencia de la objetivación que como toda acción humana, supone una manipulación sobre el hecho, el fenómeno o el objeto en cuestión, para darle la apariencia de objetivo (que en el caso de este trabajo, implica hacer visible el sufrimiento, traduciéndolo en algo real, verdadero y legítimo) (Bourdieu, 1984)

${ }^{4}$ La efectividad comunicativa, está dado, en este caso, por la legitimidad que el observador le otorga al dolor como proceso de objetivación del sufrimiento.
} 


\section{SEe}

nuevo escenario caracterizado por la gran asimetría de fuerzas, visibles por un lado, en la fragmentación y la pérdida de poder de los sectores populares y amplias franjas de las clases medias; y por otro lado, en la concentración política y económica de las elites de poder internacionalizado (Svampa, 2008:76).

De esta manera, las reformas "estructurales" impulsadas por el neoliberalismo como parte fundamental en su funcionamiento, operaron como una "modernización excluyente", donde las decisiones económicas se concentraron en grupos e intereses oligopolizados y transnacionalizados. (Calderón, 1990). La "gran asimetría de fuerzas" de la que habla Svampa se materializa en el silenciamiento y en la represión de las mayorías, desactivando su capacidad de decidir sobre sus vidas.

El elemento transversal al conflicto que han hecho visible los estudiantes chilenos, es el rol del Estado respecto del aseguramiento de la educación como un derecho. Así, el movimiento estudiantil apunta en última instancia a "redimensionar la acción propiamente política vinculada al papel del Estado" (Mirza, 2006:211), se persigue por tanto, la reconstrucción de un Estado que sea entendido como un "interlocutor de las demandas sociales y como el locus de poder sobre la sociedad" (Garretón, 2002:10) y que al mismo tiempo, se enfrente a la autonomía totalizante del mercado.

La autonomía que ha adquirido el mercado ha inundado todos los ámbitos de la vida colectiva. De esta forma, los problemas sociales tienden a procesarse y abordarse desde una lógica monetaria (cálculo de inversiones: costos y beneficios) Hinkelammert (1996) afirma que "tenemos que partir de la constatación del hecho de que un solo criterio universalista se ha impuesto: el universalismo de los criterios del mercado" (Hinkelammert, 1996: 237). En este sentido, Lechner (1996) va a sostener que "las reformas estructurales en marcha desbordan ampliamente el marco económico; no sólo imponen una economía de mercado, sino que van generando una verdadera 'sociedad de mercado' con nuevas actitudes, conductas y expectativas" (Lechner, 1996:5).

Por las razones expuestas, comienzan a emerger marcos cognitivos ${ }^{5}$ sobre los cuales las personas construyen el malestar, el que es posible asociar a la

\footnotetext{
${ }^{5}$ Los marcos cognitivos refieren al conjunto de esquemas interpretativos que operan sobre el mundo, seleccionando, priorizando objetos específicos, situaciones, eventos, experiencias y secuencias de acción. En este sentido, mediante los marcos cognitivos, nos hacemos representaciones e interpretamos los hechos y acontecimientos que nos rodean, al mismo tiempo de hacernos expectativas sobre estos. Los marcos cognitivos (de acción colectiva), se
} 


\section{sfe \\ SOCIEDADEEQUIDAD}

privatización de la seguridad ${ }^{6}$, del riesgo y de las oportunidades. Elementos que se significan como potenciales mecanismos de exclusión y vulneración de derechos. Lo que se traduce en una participación activa en la disputa del espacio público. El Informe de Desarrollos Humano para Chile (2004), afirma que las personas cada vez más "quieren participar de la construcción, no ser espectadores de las decisiones que otros tomen" (PNUD, 2004:15). Pareciera ser este, entonces, el origen del sufrimiento que embarga a los estudiantes chilenos y sus familias.

La desigualdad, la segregación, la exclusión y la escasa participación política, se constituyen en elementos centrales al momento de preguntarse por el sufrimiento de los estudiantes chilenos.

\section{El Sacrificio: “dar la vida por la educación”}

El Sacrificio (Sacrum Facere) dice relación con la producción de lo sagrado. En otras palabras, es dotar de sentido y valor algo. De esta forma, el sacrificio "es una acción social específica, que hace de la inmolación de la víctima una fuente de creación de valor" (Morandé, s/f: 9).

El sacrificio emerge y golpea la modernidad recordándole su salvaje y oscuro pasado. Pretérito de horrores que avergüenza al hombre civilizado ${ }^{7}$, ahora creador del orden y no mero administrador de éste.

En este sentido, el sacrificio se configura como una amenaza al proyecto ilustrado y a la naturaleza humana capaz de alcanzar el bienestar y la paz social, tan sólo mediante la fuerza de la razón.

La paradoja está en que el funcionamiento de la sociedad moderna exige de "sacrificios" a los individuos, en tanto estos deben cumplir el rol asignado y no otro. Es así que frente a la imposibilidad de eliminar el sacrificio, las sociedades modernas lo administran y lo sitúan en la esfera de la conciencia. Freud (1970), pensaba que

refieren a "esquemas que inspiran y legitiman las actividades y campañas no ya desde un individuo, sino de un movimiento social" (López, 2002: 31).

${ }^{6}$ El Informe de Desarrollo Humano de 1998, ya informaba del malestar de los chilenos, el cual estaba vinculado a una tendencia de procesar y de abordar los problemas (sociales) a partir de su monetarización, es decir, traduciéndolos a un mero cálculo de inversiones: costos y beneficios. El resultado de esta lógica es la privatización de la seguridad y las oportunidades. (PNUD, 1998).

${ }^{7}$ Para Elías (1990), el carácter civilizado del ser humano, estaba dado por un cambio, en términos de evolución de su emotividad. Dicho cambio opera a partir de un proceso de regulación de las emociones individuales por medio de coerciones internas o externas que se in-corporan y luego se expresan en las diversos actividades humanas. 


\section{s\&e \\ SOCIEDADEEQUIDAD}

era justamente el sacrificio permanente, el origen del malestar social, en tanto el 'hombre civilizado', se ve obligado a cambiar parte de su felicidad por seguridad. Así, la seguridad que se funda en un proceso de con-vivencia armónica de los miembros de una colectividad, se separa, cuando menos, de la gratificación que se puede alcanzar mediante la satisfacción de los impulsos. Sin embargo, esta renuncia es interpretada como un acto racional que posibilita el progreso social y el bien común.

De este modo, las sociedades modernas se encargan de manejar la tensión que emerge con los actos sacrificiales, esto a saber cómo un acto destructivo puede traducirse en un bienestar colectivo.

En las sociedades tradicionales el sacrificio es siempre una "celebración colectiva", en tanto es un acto del que ningún miembro de la comunidad podía restarse, ya que comprometía a todos e inundaba todos los ámbitos de la vida social.

El sacrificio es así el momento culminante de una fiesta donde se dilapidan de manera ritual recursos económicos. No sólo es gasto la destrucción física de la víctima o su sustituto simbólico, sino también el conjunto de recursos destinados a la producción de objetos sagrados para la fiesta. No tiene sentido, obviamente, ofrecer como obligación lo que no sirve, sino aquello que tiene valor (Morandé, s/f: 17).

En las sociedades modernas el sacrificio refiere a una obligación moral fruto de un acto reflexivo. En este sentido, es una obligación que se autoimpone un individuo, quien ha decidido y aceptado en conciencia entregarse a sí mismo (como víctima), para que la sociedad como un todo se vea beneficiada. De esta manera, afirma Morandé, la figura del verdugo es suprimida, ya que víctima y verdugo es el mismo individuo.

Ahora bien, la ética kantiana, en tanto una moral universal fundada en el deber (imperativo categórico), permite aproximarse al gozo que debiera sentir quien realiza el sacrificio de cumplir con el rol asignado, esto ya que transforma su autodonación en felicidad para todos (Morandé, s/f). Sin embargo, la modernidad exige discreción universal en el cumplimiento de los roles, nada de heroísmos que lleven al extremo el sacrificio y pueda ser interpretado como un acto de "desobediencia civil".

\footnotetext{
${ }^{8}$ Pressacco (2010) desarrolla un interesante recorrido conceptual por distintos autores que analizan el concepto de desobediencia civil.
} 


\section{SEe}

Marcone (2009) señala que entre los elementos que identifican la desobediencia civil se encuentran, el carácter colectivo, moralmente fundamentado, público, contrario a la legalidad, consciente y pacífico de la acción. Que violando normas jurídicas concretas, busca producir un cambio parcial en las leyes, en las políticas o en las directrices de un gobierno. En la misma línea se encuentra Arendt (1988), cuando señala que la legalidad de las acciones queda abierta a múltiples dudas cuando un grupo significativo de ciudadanos se convence que los canales normales de cambio no funcionan, o que sus quejas no serán oídas o no darán lugar a transformaciones. De esta forma, la desobediencia civil opera cuando el principio de justicia se considera vulnerado. Situación que se percibe como una amenaza, y que se traduce en un sentimiento de minusvalía.

Así, la huelga de hambre, en tanto, desobediencia civil, es un acto consciente que desafía la ley con argumentos morales.

De este modo, se puede afirmar que la huelga de hambre se configura como un acto sacrificial moderno, ya que los jóvenes estudiantes en un acto reflexivo ${ }^{9}$, se exponen al dolor para hacer visible el sufrimiento que les afecta. Por lo tanto, el escenario frente al que estaríamos es el de una autodonación cuyo resultado será el beneficio colectivo. Así "el dolor no es un bien, es una prueba del mal del que es susceptible que resulte un bien”. (Brossat, 2008:62).

Otro elemento significativo del carácter sacrificial de la huelga de hambre, es el de disponerse como una "ceremonia colectiva", ya que opera bajo lógicas de solidaridad frente a quien dona su cuerpo y lo expone al dolor. Esto, hace emerger disputas en la construcción de marcos cognitivos que explicitan y reafirman el conflicto. De esta manera, la huelga de hambre se transforma en una acción colectiva contenciosa ${ }^{10}$ en el marco de un movimiento social.

Así, la visibilización del sufrimiento mediante el dolor, permite la emergencia de un elemento dramático, que se traduce en participación activa del público, tanto en la posición que éstos asumen en el conflicto, como los sentimientos y emociones que vivencian al ver como los jóvenes pasan a ser simples cuerpos sin garantías, expuestos a la violencia y a la desolación (Brossat, 2008).

\footnotetext{
${ }^{9}$ El carácter reflexivo de los sujetos (desde la perspectiva de los movimientos sociales) se sostiene en la "capacidad para producir una controversia respecto de un estado de cosas cuya legitimidad y sentido normativo se daban por hechos antes de que surgiese el movimiento, lo cual ya no sucede después" (Laraña, 1999:87).

${ }^{10}$ La acción colectiva contenciosa "es utilizada por gente que carece de acceso regular a las instituciones, que actúa en nombre de instituciones nuevas o no aceptadas y que se conduce de un modo que constituye una amenaza fundamental para otros o las autoridades" (Tarrow, 2004:24).
} 


\section{S\&e}

El otro componente de la huelga de hambre propio de un acto sacrificial, es el valor social que tiene la donación. En este sentido, lo que se entrega es un "cuerpo joven y lleno de fuerzas". El cuerpo es el lugar donde residen las fuerzas. Estas son a su vez, el objeto de la explotación capitalista en tanto posibilidad de apropiación y obtención del plusvalor. Scribano, Eynard y Huergo (2010) afirman que "Entre todas las formas de organización social posibles, el capitalismo (y específicamente su fase imperial) se basa en la expropiación del plus de energías producidas por los hombres en el proceso de extracción, creación, reproducción y circulación de las mismas" (Scribano, Eynard y Huergo, 2010: 26-27).

De esta forma, la huelga de hambre, se inscribe dentro de la desobediencia civil, de alto impactos social, en razón de que es una medida que puede ser leída como un "rechazo público, consciente, colectivo y pacífico a acatar leyes o políticas gubernamentales consideradas injustas o inmorales" (Marcone, 2009:40). Esto debido a que en el marco de una sociedad capitalista y de consumo, la huelga de hambre no es funcional a la política de explotación de los cuerpos y cuestiona el principio fundamental en el que se sustenta la frágil democracia chilena, a saber, "la plena libertad de consumir".

Ahora bien, ¿Es legítima la huelga de hambre en contextos democráticos?, ¿por qué la huelga de hambre incomoda tanto a los sectores dominantes, al punto, no sólo de invisibilizar y silenciar a los huelguistas, sino también de condenarla a la inexistencia?

Brossat (2008) afirma que en las sociedades modernas emerge un enfoque anestésico. En este sentido, comenta "pasamos de un mundo donde el hombre deberá aprender a enfrentar el dolor sufrido, a resistirlo, domesticarlo, incluso magnificarlo-por ser parte integrante de su destino-, a otro universo, donde deberá hacer valer su derecho para llevar una existencia alejada de estas pruebas, premunidos contra ellas" (Brossat, 2008:65). La sociedad moderna, se entiende como una sociedad de derechos, donde estos están "destinado a preservar la integridad y asegurar la inmunidad, es decir, a des-exponer" del dolor (Brossat, 2008:16). En este sentido el "proceso de civilización" enunciado por Elías (1990) se ha articulado en función de las demandas de la sociedad, por limitar cada vez más las amenazas reales entre los seres humanos alejando los cuerpos del dolor, de la violencia o de riesgos innecesarios. El primer paso para alcanzar este objetivo, es lograr el control de los impulsos y el dominio sobre las emociones. Estas renuncias se materializan mediante la monopolización de la violencia física por parte del Estado, funcionando de ahora en más, como 'castigador' y 'protector' a la vez.

Dicho esto, se puede afirmar que el “dolor” es una categoría política sumamente poderosa, ya que como hemos anunciado, difícilmente, alguien se puede sustraer de él. Es por esto, que el reconocimiento de la huelga de hambre da cuenta de un problema político, por lo que es preferible negar su existencia, silenciar o 


\section{S\&e \\ SOCIEDADEEQUIDAD}

reprimir. Esto queda demostrado en las afirmaciones del ministro de salud, Jaime Mañalich, quien declaró, después de que los estudiantes de Buin depusieran la medida, que los casos eran "absolutamente falsos, esos jóvenes no estuvieron en huelga de hambre, ninguna huelga de hambre es en serio hasta que se han producido consecuencias fisiológicas para la persona y eso no ocurre nunca antes de los 45 días de la huelga de hambre, salvo que sea seca". (La Nación, 25/08/2011) Casi veinte días después frente a otro grupo de huelguistas afirmó que "están en una muy buena condición de salud, de manera tal que en este momento no hay tal huelga de hambre" (El Mostrador, 13/09/2011) Esto sin atender a los informes médicos que advertían lo contrario. Más allá de esta discusión, resulta interesante observar los esfuerzos por "desacreditar"11 a los huelguistas que desarrolló el gobierno. Esto tal vez, para que Chile no fuese considerado, en el escenario internacional, un Estado democrático que no asegura la condición jurídico-política propia de la persona en su carácter ciudadano, esto es: su inmunidad.

La inmunidad nos protege potencialmente del dolor, pero no del sufrimiento. Así, los estudiantes se enfrentan, no sólo con su dolor provocado por la huelga, sino también al sufrimiento de ser ignorados y silenciados. Para Brossat (2008), en este caso, el huelguista "se descubre, ahí donde se creía sujeto -ciudadano, rehén de una indolente y cínica tanatocracia; encuentra, no al soberano que mata para afirmar o reafirmar su autoridad, sino más bien a la burocracia que hace morir por indiferencia e incompetencia" (Brossat, 2008: 97).

Frente a esta indiferencia y negación de existencia, los estudiantes respondieron: "Si no nos quieren ver, les vamos abrir los ojos", y se trasladaron desde su liceo al centro de Santiago, a una cuadra de la Moneda, y al amparo de la casa central de la Universidad de Chile. En ese lugar se mantuvieron hasta que depusieron la acción de protesta.

\section{La huelga de hambre como lucha contra la 'impotencia social'}

Para entender la razón por la cual la huelga de hambre se materializa en el marco del conflicto estudiantil, es necesario entender los factores que permiten su emergencia, estos son en primer lugar, la represión como política de Estado. En segundo, la "impotencia social" (Scribano 2007a) que se deriva del accionar represivo y contiene la acción colectiva, y por último, la criminalización de la protesta como labor permanente.

La génesis del Estado chileno está estrechamente relacionado con la doctrina portaliana de 'orden y paz social' con plena vigencia hoy en día. Es justamente a este orden y su mantención al cual se refería Lastarria cuando en 1849 escribía;

\footnotetext{
${ }^{11}$ Para Goffman, (1989) Desacreditar implica un intento por demostrar que alguien no es realmente lo que dice ser.
} 


\section{sfe \\ SOCIEDADEEQUIDAD}

La clase privilegiada pone en acción todos los medios sociales en cuanto le conviene a su defensa y conservación: arrogándose la tutela del pueblo, manifiesta desear mucho su progreso, pero no hace jamás por él todo lo que desea. Poseída como está del gobierno, muestra propender el engrandecimiento y respetabilidad de la nación, pero cifra el engrandecimiento en el orden y hace consistir el orden en conservar todo lo que existe, en no reformar y en no admitir nada de nuevo ni en ideas, ni en administración, ni en política, ni en personas (Grez, 1995:108).

La represión es el principal instrumento de las elites en el control y mantención del orden ${ }^{12}$. La represión no sólo actúa por coacción, sino que también por silenciamiento o indiferencia política. Esta última "funciona como una condena de desaparición, pero también como orden de silencio, afirmación de inexistencia, y, por consiguiente, comprobación de que de todo eso nada hay que decir, ni ver, ni saber" (Foucault, 2002:9). De esta manera, lo que Lastarria describía por aquellos años, hoy nuevamente cobra sentido en las palabras de una de las huelguistas cuando clama "llamamos a gritos al señor presidente a escuchar a los estudiantes chilenos" (El Mostrador 16/08/2011).

De esta forma, los privilegios de las elites quedan protegidos bajo pretexto de la "conservación del orden público" (Salazar y Pinto, 1999) y en razón de éste, los sectores dominantes aplican una "violencia estatalizada" (Salazar, 2010). La violencia se configura entonces, como una herramienta legítima e institucionalizada por el Estado chileno, a la cual recurrirán los sectores dominantes siempre cuando la desestabilización del orden ponga en peligro sus privilegios. Grez (2008), sostiene que la oligarquía mediante la estrategia de "guerra preventiva contra el enemigo interno" ha mostrado a los sectores dominados los costos de intentar subvertir el orden impuesto.

Durante la historia de Chile, la represión en sus dos dimensiones (acciones de violencia o silenciamiento) se ha convertido en una política de Estado, lo que se ha traducido en la naturalización de ésta y en el disciplinamiento de los cuerpos a los cuales se dirige. El origen de este último, para Foucault, está en el momento que los sujetos reproducen "por su cuenta las coacciones del poder; y las ponen en juego

12 En otro trabajo (Urzúa, 2011) estudié cómo la represión, legitimada e institucionalizada históricamente por el Estado y naturalizada por los sectores dominados, posibilita el surgimiento de determinadas emociones que se 'hacen cuerpo' en el marco de las protestas y manifestaciones políticas en Chile neoliberal. 


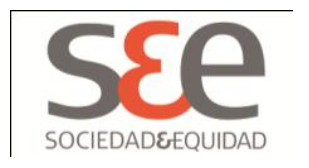

espontáneamente sobre sí mismos" (Foucault, 2008:235) generando así, una autorregulación del cuerpo y las emociones.

Para Bourdieu (1979) "la adaptación a una posición dominada implica una forma de aceptación de la dominación” (Bourdieu, 1979:392). El cuerpo se vuelve dócil y manipulable aumentando sus fuerzas en términos de utilidad económica y disminuyéndolas en términos de obediencia política (Foucault 2008). Así nos encontramos frente a un cuerpo a-someter y a-explotar.

Para Scribano (2009) esto se posibilita gracias al desarrollo de "mecanismos de soportabilidad social", los que se estructuran alrededor de un conjunto de prácticas hechas cuerpo que se orientan a la evitación sistemática del conflicto social. Al despojar al cuerpo oprimido de la conciencia de las propias fuerzas la resistencia se inhibe y se tiende "a tomar el mundo social tal cual es, a aceptarlo como natural, más que a rebelarse contra él” (Bourdieu, 1984:7). Así, los mecanismos de soportabilidad social, "se hacen cuerpo en forma de imperativos mentales y aseguran las múltiples prácticas de extracción del plus-valor” (Scribano, 2009:90).

La inhibición que se produce está conectada con lo que Scribano (2007b) llama “impotencia social”. Esta se puede entender como una condición de minusvalía respecto de la autonomía que tienen los sujetos en la transformación del mundo, lo que se traduce en la coagulación de la acción. De tal modo que la realidad social aparece como inmodificable, esto derivado de una incapacidad aceptada por los sujetos.

Al mismo tiempo los sectores dominantes articulan un discurso que tiende a criminalizar la protesta social. En este sentido, se cuestiona la libertad de manifestación y expresión, ya que se asocia a acciones delictivas. Prueba de esto, es el "sostenido avance del proceso de judialización de los conflictos, visible en la ampliación, multiplicación y forzamiento de las figuras penales, en el número de encarcelamientos y procesamientos a dirigentes y militantes sociales y sindicales, en la estigmatización mediática y social de las poblaciones y grupos movilizados (que apunta a las deslegitimación de los reclamos frente a la sociedad" (Svampa, 2008: 85)

Es así como la 'impotencia social', sumado a la 'criminalización de la protesta', dan paso a la inhibición y el autocontrol de la conducta, situación que emerge como consecuencia de sentirse permanentemente amenazado. En el caso de Chile, la amenaza es doble; por un lado, el terror de una derrota política, ideológica y militar con el golpe militar de 1973; y por otro el miedo a las prácticas neoliberales más salvajes de la región. Es justamente el miedo, lo que desactiva a las personas en sus demandas, disminuyendo así, la correlación de fuerzas "frente a los enemigos comunes". El miedo hace emerger los fantasmas de la dictadura: violencia, muerte, 


\section{s\&e \\ SOCIEDADEEQUIDAD}

desaparecidos, tortura, hambre, impunidad, acomodos, traiciones. Fantasmas que se hacen presentes, que "repiten la pérdida conflictual, recuerdan la derrota, desvalorizan la posibilidad de la contra-acción ante la pérdida y el fracaso" (Scribano, Eynard y Huergo, 2010: 27)

Sin embargo, con la huelga de hambre, acontece algo especial, ya que viene a quebrar la armonía forzada, y obliga a las personas a definirse. Contribuye de esta manera, a reconocer y reafirmar el conflicto, lo que permite, por un lado, la disputa del espacio público y por otro, el desarrollo de nuevos repertorios dentro de las formas de acciones colectivas que ponen el énfasis en el cuerpo como el locus de la expresividad.

Como se ha descrito hasta ahora, la huelga de hambre se enmarca dentro de un conjunto de acciones colectivas, en tanto acto de desobediencia civil, y opera como un eficiente mensaje simbólico que remece los marcos cognitivos de quienes se ven afectados por el conflicto y que pese a percibirlo como algo negativo, lo aceptan. En este sentido, hace visible una serie de imágenes que impactan a nivel afectivo a los observadores, generando en ellos, el rechazo de lo que 'a duras penas' era aceptado antes, haciendo que se perciba como una 'desgracia' o como 'algo injusto' necesario de cambiar. Así, "En las sensaciones e imágenes que los movimientos suscitan en el público y en sus potenciales seguidores radica gran parte de su eficiencia simbólica y su capacidad de promover el cambio en la sociedad" (Laraña, 1999:63)

\section{A modo de conclusión}

La huelga de hambre como acto sacrificial incorpora el componente colectivo de las ceremonias sacrificiales en tanto está perneada por relaciones solidarias, lo que posibilita la emergencia de marcos cognitivos que no solamente reafirman el conflicto social, sino también que orientan acciones futuras.

La huelga de hambre puede ser interpretada como un acto de desobediencia civil en tanto posee un carácter colectivo, consciente, moralmente fundado, pacífico, ilegal y público. Es una acción eminentemente política, ya que no solamente se realiza en público, sino que se dirige a principios públicos. Así, interpela desde una perspectiva moral a la sociedad respecto del principio de justicia que subyace en la ley. Escapándose de la legalidad, es capaz de ejercer reflexivamente el poder en pos de transformaciones que se visualizan como "imposibles" en el marco de una democracia atrofiada, la que se ha clausurado mediante la monopolización de los recursos y de las oportunidades.

Son estos elementos constituyentes, los que permiten que los huelguistas puedan objetivar el sufrimiento que les aqueja, entendiendo por éste, una creciente desigualdad, segregación y exclusión social que la educación en el marco de una sociedad de mercado pareciera generar. 


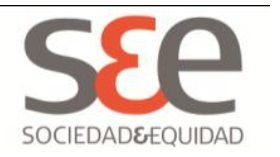

La huelga de hambre es un grito de privación radical de las necesidades humanas, que pone en peligro la sobrevida y por eso mismo tienen un mayor auditorio. En el marco de los principios democráticos in-corporados, el espectáculo se vuelve grotesco, y se convierte en un escándalo social. El escándalo social hace visible la acción y la llena de significado, la hace inteligible a los ojos de un público que conoce, de seguirse fielmente la acción, el posible desenlace. Es a raíz de esto, que la huelga de hambre se constituye en una herramienta de ato impacto social, ya que posibilita la emergencia de discursos, emociones y acciones de apoyo o rechazo, pero difícilmente de indiferencia. Con el tormento del cuerpo se pretende hacer visible el horror, la irracionalidad y la insensatez de una vida-a-destruir.

La huelga de hambre, es una decisión personal que endosa la responsabilidad a la sociedad toda. Llama a no cometer el crimen del que deja morir a otro, llama a solidarizar con un cuerpo que sufre. De esta forma, al colocar la tragedia del dolor en escena (en el marco de una sociedad anestesiada) se rompe el orden social regular, por lo que los sectores dominados comienzan a disputar el espacio público, reafirmando el conflicto y logrando un reconocimiento social de éste.

De esta forma, la huelga de hambre, que los estudiantes chilenos han desarrollado en el marco de las protestas por la educación, se configura como una ruptura de la normalidad que reafirma el conflicto y lo hace visible. Opera como un acto reflexivo que busca romper con la impotencia social que inhibe la acción política colectiva.

Su carácter estratégico reside en la autonomía que pueden adquirir los sectores dominados ya que lo único que hay entre estos y la acción de corte sacrificial es el propio cuerpo, arma fundamental en la disputa del espacio público.

El espacio público se ha comprendido tradicional $\neg$ mente como el escenario en el que se desenvuelven los conflictos, pero como se ha observado, en el marco de la huelga de hambre, no sólo es un medio, sino un fin en sí mismo. En otras palabras, el espacio público también está en disputa. De esta forma, la visibilidad de la huelga de hambre permite dar a conocer que una norma es objeto de controversia pública, y al mismo tiempo socializar al público las definiciones comunes que han adoptado quienes participan y quienes acompañan la acción.

Al hacer visible el conflicto, se hacen visibles también los cuerpos oprimidos. Así, aquellos que carecen de poder, los que habían sido silenciados y olvidados, comienzan a hablar, a ser vistos, y a ser escuchados, no sólo por quienes se oponen al disfrute de la vida de las mayorías, sino también por aquellos 'sus iguales', quienes se reconocen en una experiencia de sufrimiento, que ha sido objetivada por medio del dolor físico. De esta forma, la huelga de hambre opera como un espejo en el que se mira la sociedad haciéndose conciente de sus problemas y limitaciones (Laraña, 1999), y su imperiosa necesidad de pugnar por un cambio social. 


\section{S\&e}

\section{Referencias Bibliográficas:}

Arendt, Hannah. (1988). La crisis de la República. Madrid: Taurus.

Bourdieu, Pierre. (1984). “Espacio social y génesis de clases”. Sociología y cultura. México D.F.: Grijalbo.

Bourdieu, Pierre. (1979). La distinción. Criterios y bases sociales del gusto. Madrid: Taurus.

Brossat, Alain. (2008). La democracia inmunitaria. Santiago: Palinodia.

Calderón, Fernando. (1990). “Potenciar la Sociedad para consolidar la democracia”. En Movimientos Sociales y Política: El desafío de la democracia en América Latina. Grupo de trabajo "Movimientos sociales y Participación popular" de CLACSO. Santiago: CES Ediciones.

Elías, Norbert. (1990). El proceso de la civilización: investigaciones sociogenéticas y psicogenéticas. Buenos Aires: Fondo de Cultura Económica

Foucault, Michel. (2008). Vigilar y castigar. Buenos Aires: Siglo XXI.

Foucault, Michel. (2002). La historia de la sexualidad. La voluntad de saber. Buenos Aires: Siglo XXI.

Freud, Sigmund. (1970). El malestar en la cultura. Madrid: Alianza Editorial.

Garretón, Manuel. (2002). “La transformación de la acción colectiva en América Latina” Revista $N^{\circ}$ 76, CEPAL: 7-24. 


\section{S\&e}

Goffman, Erving. (1989). Estigma. La identidad deteriorada. Buenos Aires: Amorrortu.

Grez, Sergio. (2007). “La guerra preventiva: Escuela de Santa María de Iquique. Las razones del poder." Eco Pampino, № 30, Agosto 2007: 1-9. [Disponible en línea] <http://www.albumdesierto.cl/eco/pdfs/artic30.pdf>. Última revisión marzo 2012.

Grez, Sergio. (1995). La cuestión social en Chile. Ideas y debates precursores (18041902). Santiago: Ediciones Dirección de Bibliotecas, Archivos y Museos.

Hinkelammert, Franz. (1996). El mapa del emperador. Determinismo, caos, sujeto. San José: DEI.

Lechner, Norbert. (1996). "Las transformaciones de la política”. Revista Mexicana de Sociología, volumen $58, \mathrm{~N}^{\circ} 1: 3-16$.

Marcone, Julieta. (2009). "Las razones de la desobediencia civil en las sociedades democráticas", Revista Andamios, volumen 5, №10, 2009: 39-69. [Disponible en línea] <http://www.uacm.edu.mx/sitios/andamios/num10/dossier3.pdf >. Última revisión marzo 2012.

Mirza, Christian. (2006). Movimientos sociales y sistemas políticos en América Latina: La construcción de nuevas democracias. Buenos Aires: CLACSO.

Morandé, Pedro. (s/f). El sacrificio como categoría económica. Bases para la comprensión sociológica del papel del sacrificio en la polis. Santiago: Instituto Chileno de Estudios Humanísticos.

PNUD, (2004). Informe de Desarrollo Humano en Chile. “El poder: ¿para qué y para quién?" Sinopsis. Para aprovechar las oportunidades de Chile: más poder para todos: 


\section{SEe}

15-28. [Disponible en línea] <http://www.pnud.cl/publicaciones/IDH-2004.pdf>. Última revisión marzo 2012.

PNUD, (1998). Informe de Desarrollo Humano. Las paradojas de la modernización, capitulo 10. La seguridad humana en Chile, pp. 209-224, Santiago, Chile. [Disponible en línea]

<http://www.desarrollohumano.cl/textos/sin1998/PDF\%201998/l\%20Cap1.pdf>. Última revisión marzo 2012.

Pressacco, Carlos. (2010). “Estado de Derecho y Desobediencia civil”. Polis [online]. Volumen 9, número 27, 2010: 501-521. [Disponible en línea] <http://www.scielo.cl/pdf/polis/v9n27/art23.pdf>. Última revisión marzo 2012.

Salazar, Gabriel. (2010). Diego Portales. Monopolista, sedicioso, demoledor (Juicio ciudadano a un antidemócrata). Santiago: Editorial Usach.

Salazar, Gabriel, Pinto Julio, 1999. Historia contemporánea de Chile II. Actores, identidad y movimiento. Santiago: Lom.

Scribano, Adrián. (2009). “Acciones colectivas, movimientos y protesta social: preguntas y desafíos" Revista "Conflicto Social”. Programa de Investigaciones sobre Conflicto Social (IIGG-UBA), $\mathrm{N}^{\circ}$ 1, Año 2, 2009: 86-117. [Disponible en línea] <http://www.webiigg.sociales.uba.ar/conflictosocial/revista/01/0105_scribano.pdf. Última revisión marzo 2012.

Scribano Adrián. (2007a). “¡Vete tristeza... viene con pereza y no me deja pensar! Hacia una sociología del sentimiento de impotencia. En Contigo Aprendí...Estudios 


\section{S\&e}

Sociales de las Emociones. Luna, R. y Scribano, A. (Compiladores), pp. 21-42, Córdova, Argentina. [Disponible en línea]

<http://www.accioncolectiva.com.ar/sitio/documentos/ascribano2007c.pdf>. Última revisión marzo 2012.

Scribano, Adrián. (2007b). “La Sociedad hecha callo: conflictividad, dolor social y regulación de las sensaciones" En Mapeando Interiores. Cuerpo, Conflicto y Sensaciones. Adrián Scribano (Compilador) CEA-UNC - Jorge Sarmiento Editor, pp.118-142, Córdova, Argentina. [Disponible en línea] <http://www.accioncolectiva.com.ar/sitio/documentos/ascribano2007b.pdf>. Última revisión marzo 2012.

Sribano, Adrián, Eynard, Martín, Huergo, Juliana. (2010). “Alimentación, energía y depredación de los bienes comunes: la invisibilidad de la expropiación colonial”. Boletín ONTEAIKEN: “Un bosquejo conceptual del estado actual de la sujeción colonial” $\mathrm{N}^{\circ}$ 9, Año 5, Junio 2010: 26-45. [Disponible en línea] <http://www.onteaiken.com.ar/ver/boletin9/1-1.pdf>. Última revisión marzo 2012.

Svampa, Maristella. (2008). Cambio de época: Movimientos sociales y poder político. Buenos aires: siglo XXI editores y CLACSO.

Tarrow, Sidney. (2004). El poder en movimiento. Los movimientos sociales, la acción colectiva y la política. Madrid: Alianza Editorial.

Urzúa, Sergio. (2011). “Cuerpos en confrontación. Hacia un análisis del cuerpo y las emociones en la manifestación política en Chile neoliberal”. Revista Persona y Sociedad, volumen 25, número 2, Agosto 2011:101-123. [Disponible en línea] 
Rev. Sociedad \& Equidad № 4, Julio de 2012. Pp. 3-21

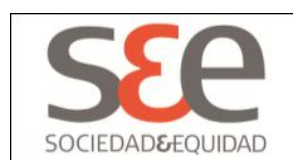

http://www.personaysociedad.cl/wp-content/uploads/2012/06/PyS-XXV-2-101123.pdf. Última revisión marzo 2012. 